\title{
A life cycle assessment of environmental and economic balance of biochar systems in Quebec
}

\author{
Baishali Dutta • Vijaya Raghavan
}

Received: 9 March 2014/ Accepted: 15 April 2014/Published online: 8 May 2014

(c) The Author(s) 2014. This article is published with open access at Springerlink.com

\begin{abstract}
A life cycle analysis (LCA) for pyrolysis biochar systems was carried out to determine greenhouse gas balance, carbon cycling, and the economics of biochar production from different agricultural residues and wastes. Investigating a range of feedstocks (forest residues, corn stover, etc.) provided insight into the use of biomass residues rather than bioenergy crops as biochar production substrates and the resulting energy and climate change impacts. The analyses were conducted based on various optimized pyrolysis parameters for corn fodder and forest residue. The observed reductions of greenhouse gas (GHG) emissions $\left(\mathrm{CO}_{2}\right.$ equivalent per $\mathrm{Mg}$ dry feedstock) for both corn fodder and forest residue were mainly contributed by the stable carbon in the biochar. Corn fodder showed a greater reduction in emissions than forest residue, indicating the corn fodder's greater economic potential for soil sequestration of stable carbon. The relative GHG emission analysis found that the optimization of a biomass pyrolysis system for biochar production is better suited for soil sequestration of stable carbon than as a fuel source. The economic viability of the pyrolysis-biochar system is largely dependent on the costs of feedstock production, pyrolysis, and the value of $\mathrm{C}$ offsets. The LCA reported in this study can be instrumental in assessing the environmental potential of biochar production and its application in the region.
\end{abstract}

\footnotetext{
B. Dutta $(\square) \cdot$ V. Raghavan

Department of Bioresource Engineering, McGill University, 21111, Lakeshore Road, Ste Anne de Bellevue, Montreal, QC H9X 3V9, Canada

e-mail: baishali.dutta85@gmail.com

V. Raghavan

e-mail: vijaya.raghavan@mcgill.ca
}

Keywords Life cycle analysis - Biochar - Climate change $\cdot$ Economics $\cdot$ Greenhouse gas emissions · Mitigation

\section{Introduction}

Combating global climate change and meeting the world's ever-rising energy demands are concerns which have occupied researchers all around the world. The global greenhouse gas emissions were estimated at approximately $32 \mathrm{Pg}$ in 2008 [1]. Adding to this dilemma is an everincreasing world population which is creating an enormous stress on our fragile planet. While carbon emissions increased 6 times since 1950 [1], the same 75-year span has seen the world population increase by $3 \frac{1}{1} 4$-fold to almost 7 billion in 2011, and it is expected to reach the 9 billion mark by 2050 [2].

Canada's total GHG emissions for 2008 were estimated at $702 \mathrm{Tg}$ of $\mathrm{CO}_{2}$ equivalents $\left(\mathrm{CO}_{2} \mathrm{e}\right)$, of which nearly $10 \%$ was contributed by the agricultural sector [3]. This sector generates roughly $300 \mathrm{Tg}$ of agricultural waste [4, 5]. Assuming $50 \%$ recovery of carbon from this biomass [6], one could sequester nearly $150 \mathrm{Tg}$ of carbon dioxide from the atmosphere, in the form of biochar, or about $20 \%$ of Canada's GHG emissions.

An increased need of technologies with long-term sustainable implications in the bioenergy sector has been widely acknowledged. Biochar's use as an energy source [7], as a fertilizer when mixed with soil [6], and as a means of reducing greenhouse gas emissions through the soilsequestration of carbon [8], has gained enormous attention in recent years. Moreover, biochar can also have potential positive effects on food security by reducing the amount of food crops used for biofuel production [9]. 
One of the most important current thermochemical biomass-conversion technologies, pyrolysis is a process of thermal decomposition of biomass under conditions ranging from low oxygen ( $\left.<1 \% \mathrm{O}_{2} \mathrm{v} / \mathrm{v}\right)$ to anoxia (no oxygen). It converts organics to solid (charcoal), liquid (organics), and gas $\left(\mathrm{CO}, \mathrm{CO}_{2}, \mathrm{CH}_{4}, \mathrm{H}_{2}\right)$ products. Their range and relative amounts depend on process variables such as the nature of the feedstock and the heating rate [10, 11]. Biochar production through pyrolysis has become an extremely efficient and popular technology in recent years.

Life-cycle analysis (LCA) is a technique to assess the potential environmental impacts associated with all the stages of a material, service, or product's life. The approach involves careful calculation and evaluation of parameters which might influence such impacts. As LCA consists of the assessment and characterization of products, systems, processes, and design [12], it can be said to follow a "cradle to grave" approach. Highly useful in post facto determination of the unwanted outcomes of a product's use or technology's implementation, LCAs can also serve a priori in facilitating appropriate decision-making to avoid unwanted outcomes.

A LCA was carried out by Whitman et al. [13] to evaluate corn stover feedstock production for cellulosic $\mathrm{EtOH}$ production in three corn-producing regions in Quebec for energy and greenhouse gas (GHG) impacts. In this study, in-field processes such as corn stover production, collection, transport, soil organic carbon (SOC) loss, and $\mathrm{N}_{2} \mathrm{O}$ emissions, as well as background processes of herbicide, fertilizer, seed, and fuel production and transport were considered as the system boundaries. The sensitivity analyses included the variation of the percentage of corn stover collected, contrasted a multiple-pass with a one-pass stover-grain collection system, and compared mass, economic, and system expansion allocation methods. Their results showed that the total energy impact was 931-1,442 $\mathrm{MJ} \mathrm{t}^{-1}$ dry stover collected under $15 \%$ stover collection, with stover harvest, transport, and field operations contributing most strongly to the total impact. Total GHG emissions from corn stover production and transport of stover to the ethanol facility were found to be $320-488 \mathrm{~kg} \mathrm{CO}_{2} \mathrm{e} \mathrm{t}^{-1}$ dry stover under $15 \%$ stover collection, with SOC loss, $\mathrm{N}_{2} \mathrm{O}$ emissions, and stover harvest contributing the most to the total impact. A sensitivity analysis carried out by this research revealed that the energy and GHG impacts of stover production are strongly influenced by the mass of stover collected, the use of a one-pass system, and the choice of allocation methods. Scaling-up results from the modeled system suggest that $100 \%$ of Quebec's EtOH targets could technically be supplied using corn stover feedstock, but would have negative impacts on GHG emissions and soil health [13].
Although biochar is known for its enormous potential as an alternate energy source, the environmental implications of its potential role as a tool for mitigation of greenhouse gas emissions through $\mathrm{C}$ sequestration has not been fully assessed. Consequently, an LCA of biochar production (pyrolysis) and sequestration (soil amendment) systems is warranted, as it would be undesirable to have the system actually emit more GHG than it sequesters, or consume substantially more energy than it generates [14].

There have been very few LCAs conducted to assess pyrolysis biochar systems or to quantify the GHG mitigation potential of biochar. Roberts et al. [15] conducted an LCA to estimate the energetic, economic, and climate change mitigation potential of various agricultural residue or energy crop pyrolysis feedstocks (corn stover, residential yard waste, and switch grass). They found that corn stover yielded greater energy generation and lesser GHG emissions than switchgrass, as well as showing a moderate potential to be profitable. This evaluation was dependent on the value of $\mathrm{C}$ offsets and feedstock collection costs [15].

An LCA carried out by Gaunt et al. [16], on the energy and climate impacts of biochar systems operating with bioenergy crops or crop wastes as feedstocks, showed soil amendment with biochar to reduce GHG emissions two- to fivefold more than if used solely as fossil energy offsets. Roughly half the magnitude of these reductions arose through the retention of $\mathrm{C}$ in biochar. They found the ratio of energy produced per mass of feedstock to that supplied to produce biochar through slow pyrolysis were two- to sevenfold greater than that of comparable technologies (e.g., ethanol from corn). In particular, low-temperature slow pyrolysis offers an energy-efficient strategy for bioenergy production [16].

The overall impacts of biochar for agricultural use were evaluated by Sparrevik et al. [17] through a LCA for field sites in Zambia. The study evaluated three different biochar production methods of traditional earth-mound kilns, improved retort kilns, and micro top-lit updraft (TLUD) gasifier stoves with cultivation growth basins and precision fertilization and compared to conventional agricultural methods. Although the study found beneficial aspects of biochar use in conservation farming, conservation farming plus biochar from earth-mound kilns was found to have certain negative health impacts due to the particle emissions originating from biochar production. The use of cleaner technologies such as retort kilns or TLUDs could, however, overcome this problem. The authors emphasized the need for a holistic view on biochar use in agricultural systems [17].

Woolf et al. [18] estimated the maximum sustainable technical potential of biochar to mitigate climate change. Their results show that biochar application has the maximum potential of reducing the annual net emissions of 
Fig. 1 Biochar LCA flow diagram

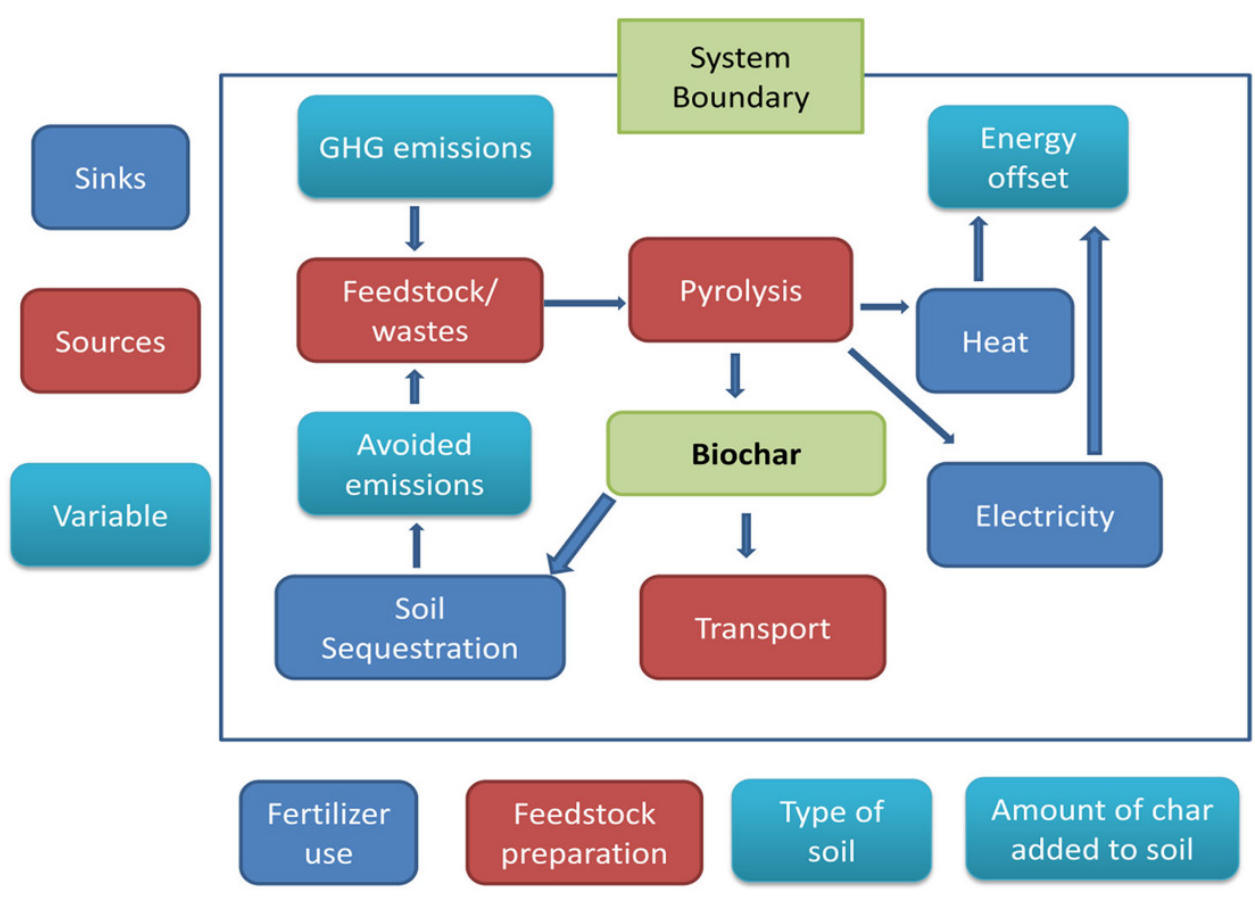

$\mathrm{CO}_{2}$, methane, and nitrous oxide by $1.8 \mathrm{Pg} \mathrm{CO}_{2}$ equivalent $\left(\mathrm{CO}_{2} \mathrm{e}\right)$, and total net emissions over the course of a century by $130 \mathrm{Pg} \mathrm{CO}_{2} \mathrm{e}$, without endangering food security, habitat, or soil conservation [18].

Given the limited extent of these studies, an LCA was carried out to assess the GHG balance, carbon cycle, and economics of biochar production from different agricultural residues, using different pyrolysis biochar systems in the Quebec region.

\section{Methodology}

Using original spreadsheets and data derived from a wide review of literature, carbon flows, greenhouse gases expressed as carbon equivalents, and energy generated were monitored. The factors taken into account were type of feedstock, transport, electricity generation through pyrolysis, and heat use.

\section{Goal and scope}

Assuming biochar production to occur through slow pyrolysis, total emissions, and emission factors used in preparing emission inventories and calculating emission reductions for particular fuels, along with the economics of biochar production from corn stover or forest residues were estimated. For a given pyrolysis system the LCA estimated the production of biochar based on $1.0 \mathrm{Mg}$ of dry biomass. The reference flows for this system, as implemented through a methodology developed in Microsoft Excel, were considered to be the mass and carbon content in the biomass feedstock.

\section{Feedstocks}

As suggested by Hammond et al. [19], feedstocks were selected on the basis of their suitability for pyrolysis, and the quantity of source material available in Quebec presently, and over the past 5 years.

\section{System boundaries}

Studies of biochar systems' wide-ranging applicationsincluding carbon sequestration, reduction of carbon-containing GHG emissions, energy production, soil enhancement, and in some cases, waste disposal-have highlighted such systems' importance [15, 19]. It was beyond the scope of this study to consider all possible boundaries associated with the production and application of biochar to soils. The objective of drawing such boundaries was to allow for the determination of factors in three categories: sources of GHG, GHG sinks, and variables (GHG emissions, Avoided emissions, Energy offsets) considered in the LCA (Fig. 1).

\section{Inventory}

The biochar considered for this LCA finds its use as a soil amendment produced through slow pyrolysis in pyrolysis units. The biochar produced is then transported to the farm for sequestration in soil. The LCA considered the following processes: 
(a) Feedstock analysis The feedstocks considered were corn fodder (corn stalk without the kernels and the ears; treated as waste) and forest residues. Biochar production data for Quebec was drawn from Statistics Canada [20]. Energy use/production and greenhouse gas emissions were calculated according to IPCC guidelines (1996) for GHG estimation [21].

(b) Pyrolysis The pyrolysis conditions and parameters chosen for this study were those of slow pyrolysis as optimized by Dutta et al. [10]. Slow pyrolysis conditions constituted heating rate of $20{ }^{\circ} \mathrm{C} / \mathrm{min}$ at optimal pyrolysis temperature and residence time of $400{ }^{\circ} \mathrm{C}$ for $12 \mathrm{~min}$.

(c) Transport The transport data were gathered from the North East Biofuel Supply Chain Carbon Intensity Assessment [22] and calculations were based on the transport of $25.5 \mathrm{Mg}$ of feedstocks from the field to the pyrolysis facility using a heavy-duty diesel truck with no backhaul [19]. The return trip loaded with the finished biochar product was accounted for in the biochar application process. Though the transport distance varied, based on requirements in Quebec, a return trip baseline of $200 \mathrm{~km}$ was used.

(d) $G H G$ sinks Heat and electricity generation were considered to be the two main GHG sinks in the present study and were included as energy offsets or co-products in the biochar production process.

Impact assessment

Computational spreadsheets were developed around the factors defined in the goal and scope, and drawing upon data derived from a wide review of the literature. The impact assessment consisted of deriving the GHG carbon equivalent and net energy generated or consumed during the progression of biochar production through the steps of feedstock accumulation, transport, and pyrolysis. In turn, this was used to calculate the climate change impacts of each process. The net climate change impact was calculated as the sum of " $\mathrm{CO}_{2} \mathrm{e}$ sequestered" and " $\mathrm{CO}_{2} \mathrm{e}$ emissions".

\section{Economic assessment}

An economic assessment estimated the cost/revenue contribution of each process in the biochar life cycle. As in earlier studies $[15,19]$, the main costs arose from feedstock collection, pyrolysis, and transport, while the revenues generated arose from the value of the biochar and the reduction in $\mathrm{GHG}$ emissions. In valuing GHG offsets, only the stable carbon in the biochar was considered.

Two revenue scenarios were investigated: low revenue $\left(\$ 20 \mathrm{Mg}^{-1} \mathrm{CO}_{2} \mathrm{e}\right)$ and high revenue $\left(\$ 80 \mathrm{Mg}^{-1} \mathrm{CO}_{2} \mathrm{e}\right)$ based on the IPCC definitions. The net profit of the biochar production system was calculated on the basis of a unit biomass of 1.0 Mg dry weight (d.w.) [15] in Eq. 1:

$\mathrm{NP}=\mathrm{BC}+E-F-T-O-C-A$,

where,

NP is the profit associated with $1.0 \mathrm{Mg}$ d.w.,

$\mathrm{BC}$ is the value derived from the biochar,

$E$ is the value of the energy created in the process,

$F \quad$ is the cost of producing and collecting the feedstock,

$T$ is the transportation cost for both the feedstock and the biochar product,

$C$ is the capital cost associated with processing a unit of the feedstock,

$O$ is the operating cost incurred for processing a unit of feedstock,

$A \quad$ is the cost of applying the biochar to the field.

The BC value was calculated as in Eq. 2 (adapted from Roberts et al. [15]):

$$
\begin{aligned}
\mathrm{BC}= & \mathrm{pPqcP}+\mathrm{pKqcK} \\
& +\alpha \delta(\mathrm{pPqBaseP}+\mathrm{pKqBaseK}+\mathrm{pNqBaseN}) \\
& +\mathrm{pGHGqGHG},
\end{aligned}
$$

where

$\mathrm{pK}, \mathrm{pN}, \mathrm{pP}$

qGHG and pGHG

$\mathrm{qcK}$, and qcP

$\alpha$ and qBaseP are, respectively, the price of potassium, nitrogen, and phosphorus fertilizers,

are, respectively, the quantity of GHG reductions associated with the biochar and the value of these reductions,

qBaseK, qBaseN are, respectively, the average quantities of potassium, nitrogen, and phosphorus fertilizers applied to a corn crop under standard, biocharfree cultural conditions, are, respectively, the quantity of potassium and phosphorus in the biochar,

is a conversion factor $\left(0.14\right.$ ha $\mathrm{Mg}^{-1}$ biochar) based on the assumption of a biochar having a $67.68 \%$ carbon content $(\mathrm{w} / \mathrm{w})$ being applied at a rate of $5 \mathrm{Mg} \mathrm{C} \mathrm{ha}^{-1}$,

is the difference in fertilizer uptake efficiency between soil amended with biochar and soil without biochar. 
In calculating the biochar's value, all of the biomass' $\mathrm{P}$ and $\mathrm{K}$ were assumed to remain present in the biochar, but made available to plants when the biochar was used as a soil amendment. The quantities of $\mathrm{N}, \mathrm{P}$, and $\mathrm{K}$ for forest residues and corn fodder were collected from various sources [23, 24], while their prices were determined based on fertilizer prices of $\$ 0.80 \mathrm{~kg}^{-1} \mathrm{P}_{2} \mathrm{O}_{5}, \$ 1.60 \mathrm{~kg}^{-1} \mathrm{~N}$, and $\$ 0.75 \mathrm{~kg}^{-1} \mathrm{~K}_{2} \mathrm{O}[25]$.

The energy generated through biochar production served to counterbalance the energy spent during the pyrolysis process and was expressed as equivalents of a conventional form of energy: in this case, natural gas. The Canadian mean natural gas prices for all sectors (Henry Hub pricing for December, 2012) were $\$ 2.88 / \mathrm{mm}$ BTU or $\$ 1.04 \mathrm{~m}^{-3}$ [26]. Syngas energy was valued at $\$ 42.81 \mathrm{Mg}^{-1}$ (d.w.) for corn fodder feedstock [15] and $\$ 30.0 \mathrm{Mg}^{-1}$ (d.w.) for forest residue feedstock [27]. Transport costs accrued with the progress of biomass transport from the field to the pyrolysis unit and of biochar from the pyrolysis unit to the field. The total transport costs for corn fodder and forest residues were $\$ 20.22$ and $\$ 15.17 \mathrm{Mg}^{-1}$ (d.w.) $[15,28]$.

Biochar application costs (A) included implement cost, fuel, and labor, at $\$ 26.69 \mathrm{ha}^{-1}$ or $5 \mathrm{MgC} \mathrm{ha}^{-1}$, or $\$ 3.62 \mathrm{Mg}^{-1}$ biochar. The operating and capital costs were calculated collectively based on figures reported by McCarl et al. [29], which included both pre-treatment and pyrolysis operational costs. These figures were chosen as being the highest among the most conservative estimates of pyrolysis facility costs.

\section{Improvement assessment}

The results of this study were used to quantify the effects of the application of biochar produced in the pyrolysis process in soil sequestration as well as a tool for climate change mitigation through reduction of GHG emissions. Thus the improvement assessment was carried out in the context of biochar production.

\section{Results and discussion}

Greenhouse gas emissions balance

A comparison of total GHG emissions from corn fodder and forest residue feedstocks and conventional fuel sources (natural gas and petroleum) [3] showed the former to generate much lower emissions than the latter (Fig. 2). Expressed on a percent reduction basis, GHG emissions from corn fodder and forest residues, respectively, were 94.2 and $92.9 \%$ less than those for natural gas, and 89.4 and $87 \%$ less than those for petroleum. It is interesting to note that a complete consideration of all emissions from

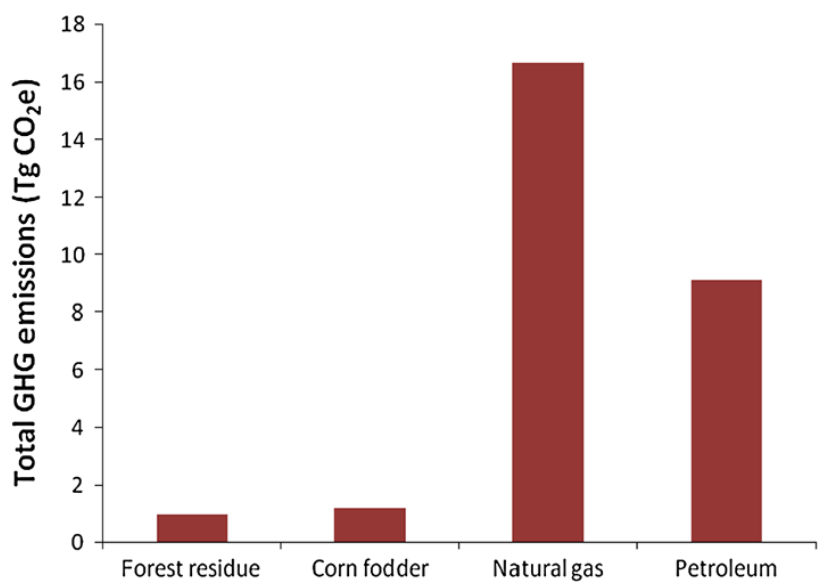

Fig. 2 Comparison of total emissions (per $\mathrm{Mg}$ of fuel) between traditional fuel sources and biofuels

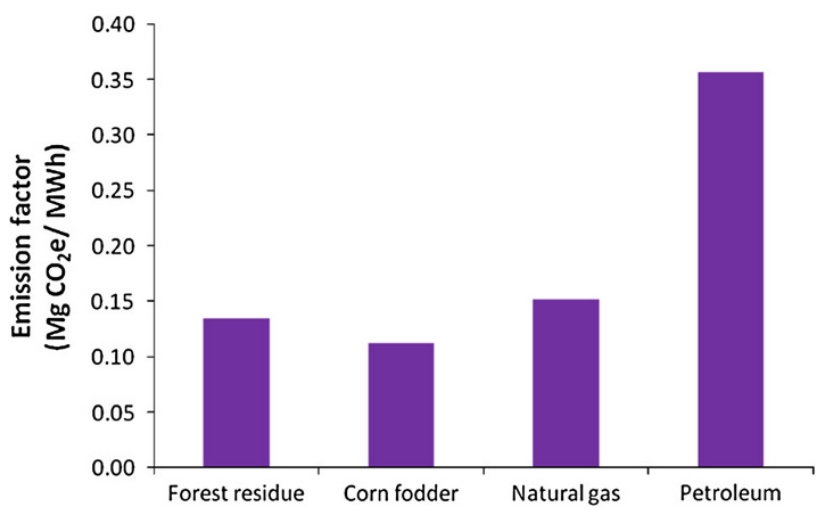

Fig. 3 Comparison of emission factors between traditional fuel sources and biofuels

using natural gas would place it at a far less attractive position than petroleum and not significantly better than coal in terms of the consequences for global warming. Some of these considerations are natural gas obtained from hydrofracking which is estimated to have $60 \%$ more emissions than for diesel fuel and gasoline, additional emissions of greenhouse gas occur during the development, processing, and transport of natural gas as well as the leakage of methane gas during production, transport, processing, and use of natural gas [30].

Greenhouse gas (GHG) emissions are most commonly calculated using emissions factors; these values relate the quantity of an emission with an associated activity [3]. Emission factors for corn fodder and forest residues were marginally lower than that for natural gas, but substantially lower than that for petroleum (Fig. 3). Although GHG emissions were greater for natural gas than petroleum, the burning of natural gas emits less carbon dioxide than from 
Fig. 4 Effect of biochar production on biomass fuel net GHG emissions
Fig. 5 Effect of biochar production on biomass fuel emission factors
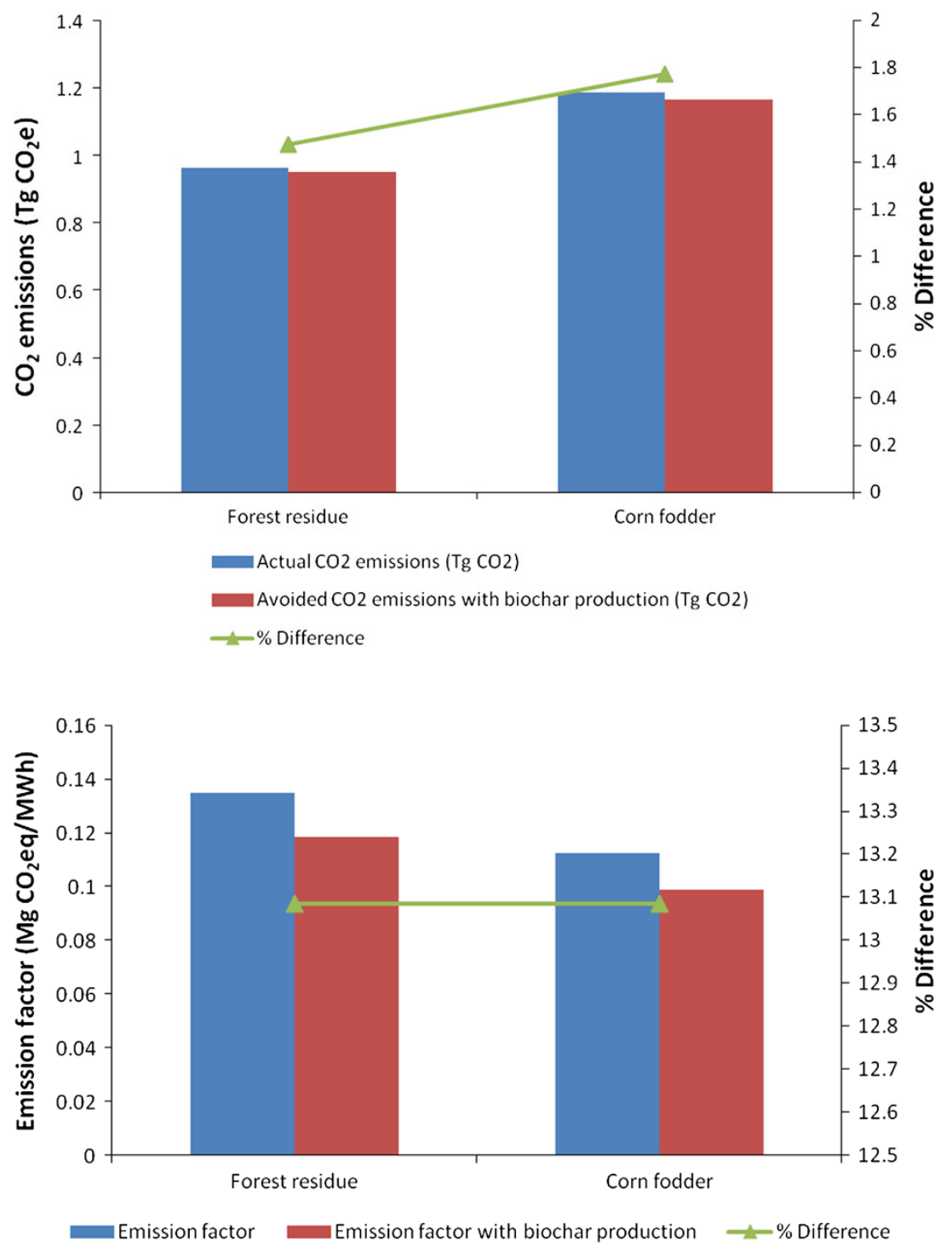

burning coal per unit of energy generated, which results in lower emissions factors for natural gas [30].

\section{Improvement assessment}

The effect of the balance of biochar vs. syngas as primary end product of biofuel production on GHG emissions from the chosen feedstocks was evaluated by calculating the percent difference between GHG emissions associated with the production of biochar and that of biofuels produced without biochar coproduction. Percent abatement of GHG emissions with biochar vs. syngas production was 1.47 and $1.77 \%$ for corn fodder and forest residues, respectively (Fig. 4). In the context of the $14 \%$ of global $\mathrm{CO}_{2}$ emissions coming from agriculture, this reduction of approximately $2 \%$ through the incorporation of biochar co production would play a significant role in the climate change mitigation efforts. In the case of emission factors, the percent reduction in emission factors for biochar (vs. syngas) production was roughly $13 \%$ for both feedstocks (Fig. 5).

\section{Contribution analysis}

A contribution assessment of the processes involved in these biochar systems indicated that GHG emissions associated with the pyrolysis stage were the highest, contributing 51.2 and $47.3 \%$ of total emissions for forest residues and corn fodder, respectively (Fig. 6). This corroborates the findings of studies in which different feedstocks were compared $[15,16]$. While a number of studies have shown that land-use changes and field emissions associated with feedstock production were the dominant processes contributing to GHG emissions [15, 16], the 
Fig. 6 Analysis of life cycle stages contributing to GHG emissions in percentage $(\mathrm{kg}$ $\mathrm{CO} 2 \mathrm{e} / \mathrm{t}$ feedstock d.w.): a forest residues, $\mathbf{b}$ corn fodder
A

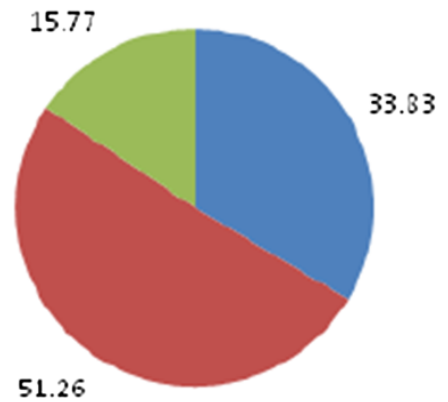

B

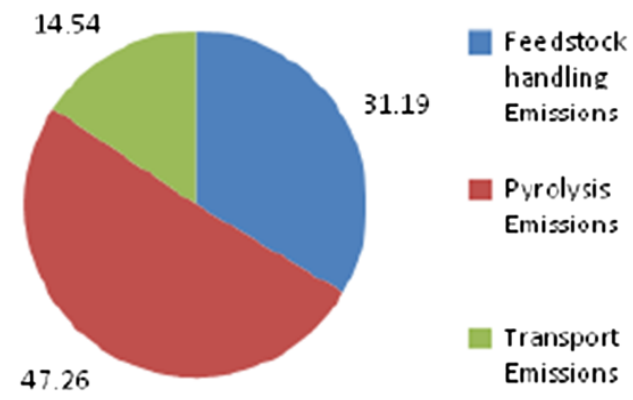

present research did not consider land-use change as a part of the feedstock production process. Other factors which may contribute to GHG emissions include transportation of biomass and biochar, and the use of machinery involved in biochar production and biochar application.

It has been suggested that the pyrolysis stage's proportionately greater contribution to GHG emissions arises from the gaseous emissions which make up part of the syngas during pyrolysis. In general, the process of pyrolysis is endothermic for temperatures $<280{ }^{\circ} \mathrm{C}$ and becomes exothermic between 280 and $350{ }^{\circ} \mathrm{C}$, where char formation takes place. Beyond $>350{ }^{\circ} \mathrm{C}$, the process once again becomes endothermic, consisting of a devolatilization stage [11, 31].

During the endothermic processes, initial energy loss is linked to the initiation of pyrolysis as well as emissions during the devolatilization process. It is assumed that roughly $10 \%$ of total energy available for conversion to electricity is required in the process and that a further $10-15 \%$ is lost in the process, partially accounting for start-up fossil fuel [11].

\section{Emissions avoided balance}

The net GHG emission reductions or carbon sinks in the life cycle of biochar systems included are reductions due to the avoidance of fossil fuel production and combustion, the generation of electricity and heat by the pyrolysis process, and the sequestration of stable biochar-C upon its use as a soil amendment. Reduction in emissions from corn fodder pyrolysis associated with soil sequestration of stable carbon and the sink represented by the electricity and heat generated were 38.6 and $44.3 \%$ greater, respectively, than those achieved with forest residues (Fig. 7).

A GHG emissions balance for the different components of the biochar system cycle (Fig. 8) shows that in the case of both feedstocks, transport emissions accounted for very little of the overall emissions. Barely noticeable alone, heat offsets were combined with the electricity generation offset to become a significant source of $\mathrm{GHG}$ emissions reduction. Thus the GHG emissions balance analysis found that the

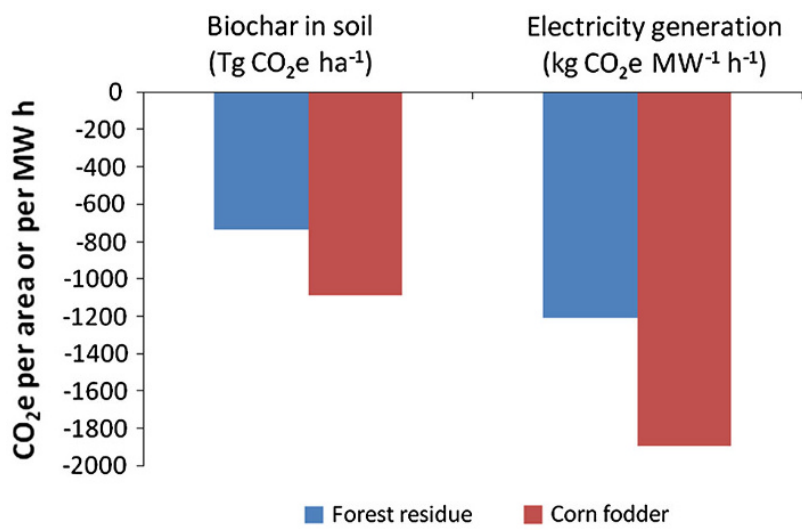

Fig. 7 Comparison of reduction in emissions (Carbon sinks) for forest residue and corn fodder

optimization of a biomass pyrolysis system towards biochar production is better suited for soil sequestration of stable carbon than for the production of a fuel source. These findings concur with the conclusions of several other studies $[16,19]$. This in turn would support the implementation of biomass pyrolysis units associated with biochar amendments to agricultural soil as a strategy to reduce greenhouse gas emissions and deliver environmental benefits.

The net avoided emissions were calculated as the total emission abatement from biomass generating pyrolysis with biochar applied to soil and electricity generation minus the sum of emissions from feedstock handling, pyrolysis emissions, and transport emissions. While total GHG emission reductions through soil amendment with biochar and electricity and heat generation during pyrolysis were higher for corn fodder than forest residue (Fig. 9), total emissions were also higher for corn fodder. As a result, the net reduction in emissions $\left(\mathrm{Gg} \mathrm{CO}_{2} \mathrm{e} \mathrm{Mg}^{-1}\right.$ of feedstock) for forest residue was greater, making it a more suitable source for biomass pyrolysis for GHG reductions.

\section{Economic assessment}

In the low revenue scenario $\left(\$ 20 \mathrm{Mg}^{-1} \mathrm{CO}_{2} \mathrm{e}\right.$; Fig. 10), net costs incurred for biochar production through pyrolysis of 
Fig. 8 Relative GHG emissions for different components of the biochar system cycle

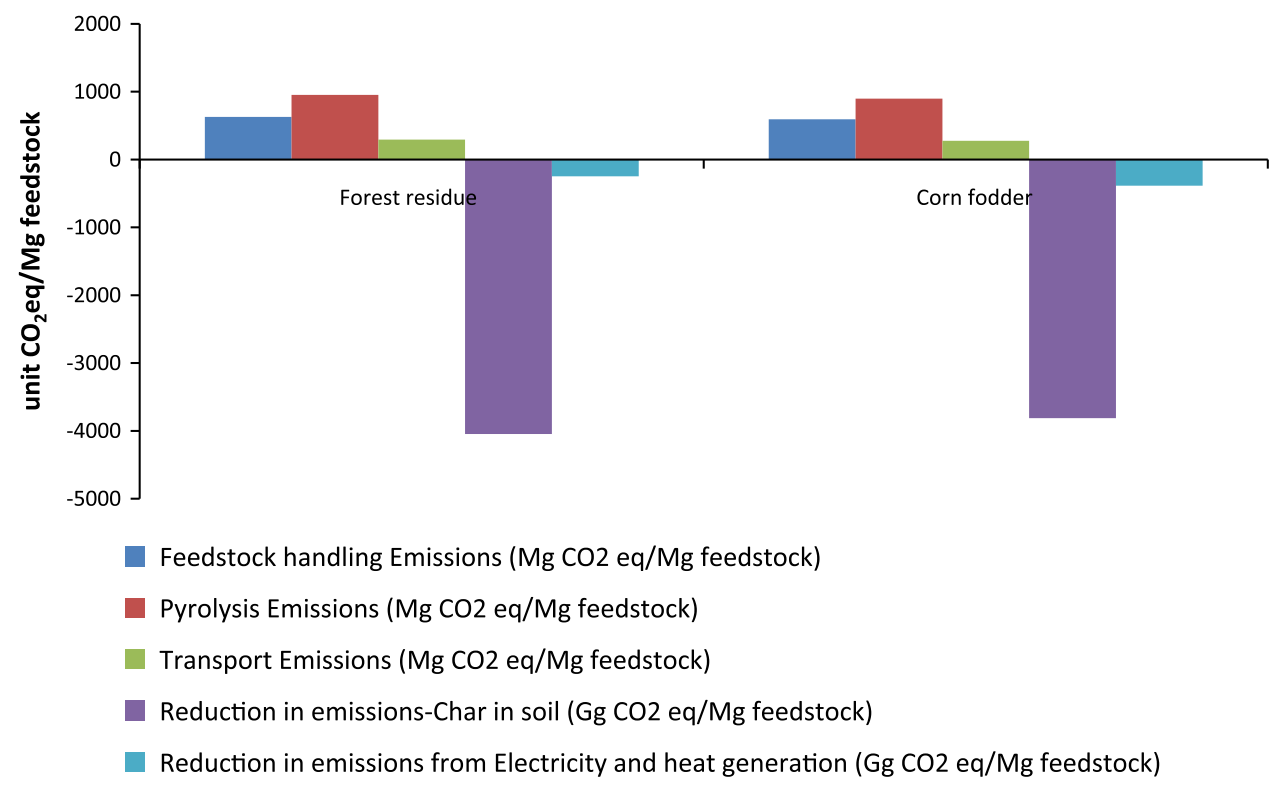

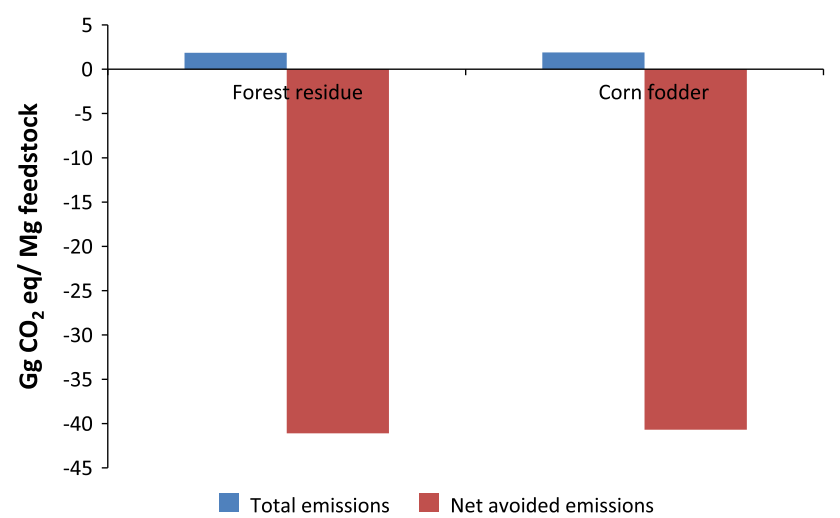

Fig. 9 Comparison of GHG balance for corn fodder and forest residue

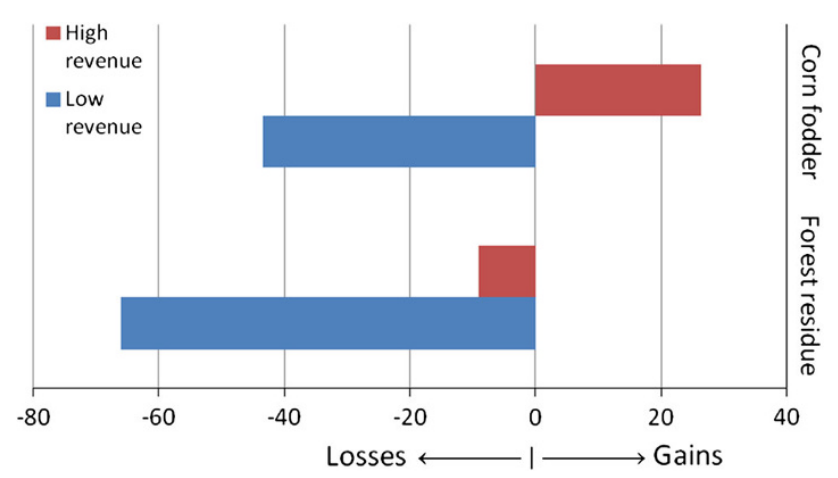

Fig. 10 Net gains or losses $\left(\$ \mathrm{Mg}^{-1}\right)$ for each feedstock

both corn fodder and forest residue were $\$ 43$ and $\$ 66 \mathrm{Mg}^{-1}$ biomass (d.w.), respectively, indicating that these systems' economic viability remained quite poor. Comparatively, for the high revenue scenario $\left(\$ 80 \mathrm{Mg}^{-1}\right.$
$\mathrm{CO}_{2} \mathrm{e}$ ), forest residue continued to be a poor economical option with net costs of $\$ 9 \mathrm{Mg}^{-1}$ biomass, whereas corn fodder showed gains of $\$ 26 \mathrm{Mg}^{-1}$, indicating a moderate potential for economic viability (Fig. 10).

Although the biochar systems for both feedstocks do provide energy offsets in terms of electricity and heat as well as help in GHG abatement, their economic potential requires further improvement. An analysis of the net costs of each life cycle stage for the low and high revenue options (Fig. 11) indicates that the cost of feedstock collection and operating costs of the biochar production unit were the main impairment to financial viability. Despite both the feedstocks incurring similar levels of costs during the "expenditure" stages, corn fodder is a more suitable candidate given its higher biochar value (Fig. 11). It is interesting to note that transport costs have very little effect on the net costs for either revenue scenario.

Results indicating that corn fodder is one of the more economically feasible feedstocks have been widely reported. Roberts et al. [15] found that the late corn stover had a greater economic viability than even high-energy alternatives like switchgrass, which was not found to be profitable. The authors surmised that this was due to the low value associated with the latter's reduction of $\mathrm{CO}_{2} \mathrm{e}$ units.

Furthermore, if we compare the biochar systems of corn fodder and forest residue (Fig. 12), it is interesting to note that although their potential to reduce GHG emissions is almost equivalent, the net terms of profits associated with corn fodder makes it a more suitable candidate and would allow it to gain better carbon credits in a competitive market scheme. 
Fig. 11 Comparison of net costs $\left(\$ \mathrm{Mg}^{-1}\right)$ by life cycle stage for two feedstocks and two revenue scenarios: a low, b high

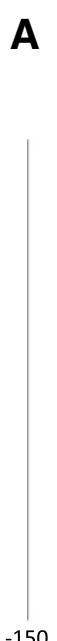

B

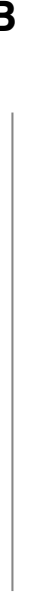

$-150$
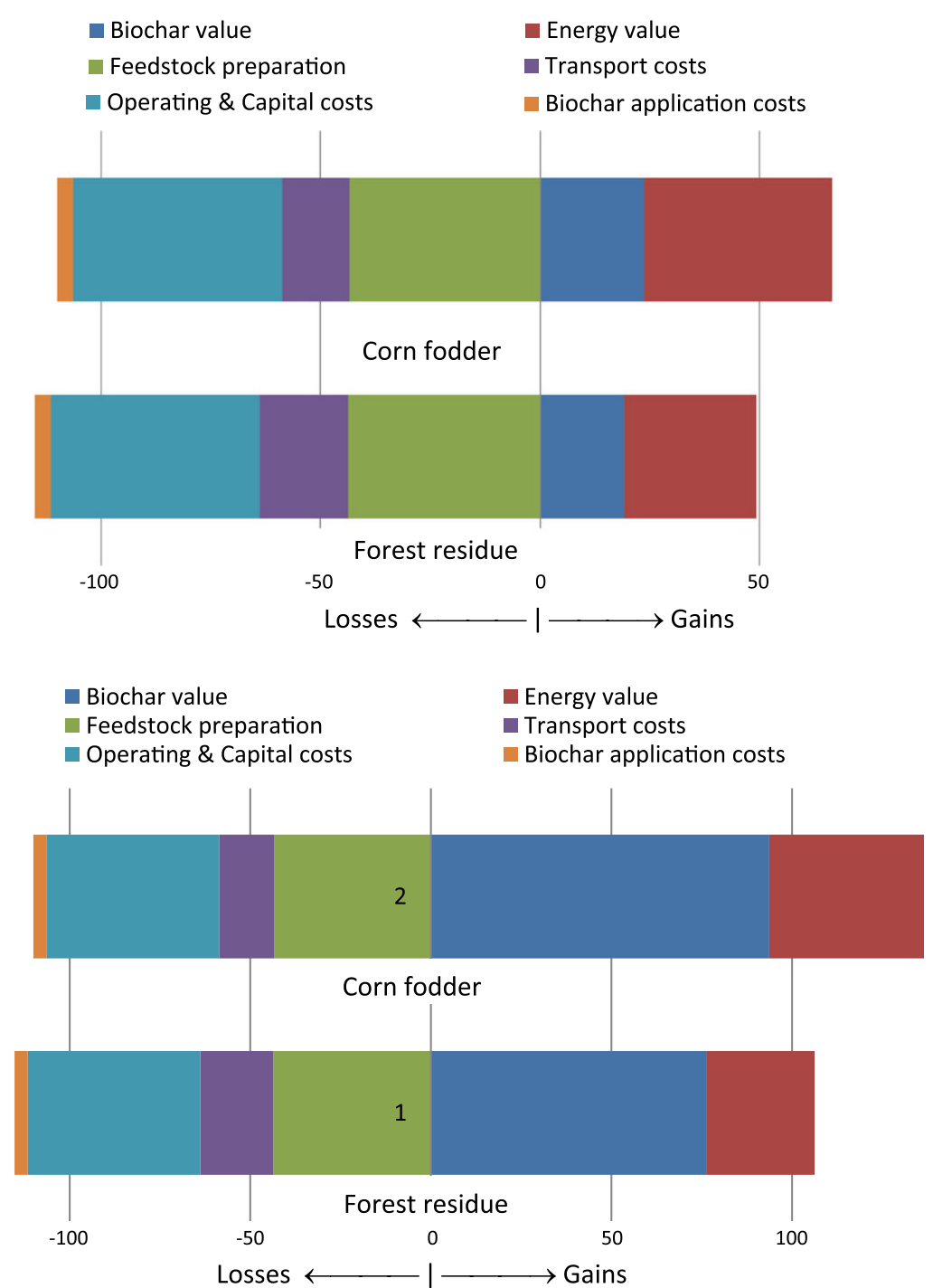

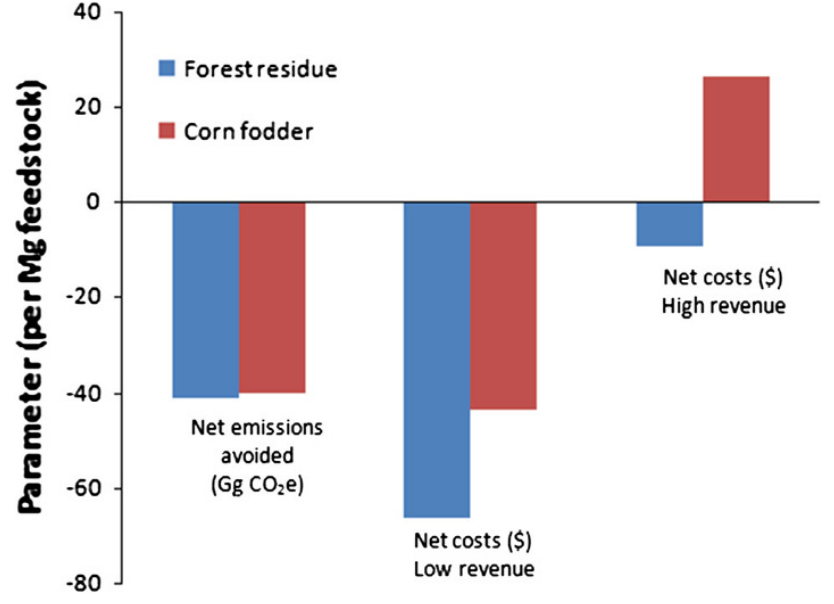

Fig. 12 Comparison of feedstocks: economic vs. GHG balance

\section{Conclusion}

This research highlights the importance of a life cycle analysis to estimate the full life-cycle GHG emission balance and economic feasibility of biochar systems. This analysis was conducted based on various optimized pyrolysis parameters for agricultural wastes of corn fodder and forest residue. The GHG emissions avoided for both corn fodder and forest residue showed a reduction in emissions $\left(\mathrm{CO}_{2} \mathrm{e} \mathrm{Mg}^{-1}\right.$ feedstock d.w.). The stabilized carbon in the biochar was the main contributor to these reductions. The reductions in emissions attributable to soil sequestration of stabilized carbon in biochar ( $\mathrm{C}$ sink) and to electricity and heat generation during pyrolysis were, respectively, 38.6 and $44.3 \%$ greater for corn fodder than forest residue. A relative GHG analysis found that the optimization of a 
biomass pyrolysis system for biochar production to be better suited to soil sequestration of stable carbon than as a fuel source. The economic viability of the pyrolysis-biochar system is largely dependent on the costs of feedstock production, pyrolysis, and the value of $\mathrm{C}$ offsets. Corn fodder at a net cost of $\$ 26 \mathrm{Mg}^{-1}$ feedstock showed a moderate potential for economic viability compared to forest residue.

Acknowledgments The authors would like to gratefully acknowledge the financial support of NSERC (Natural Sciences and Engineering Research Council), Canada, Le Fonds de recherche du Québec-Nature et technologies (FQRNT) and Schulich Canada Graduate Scholarships.

Authors' contributions BD carried out a thorough literature review for data collection on existing biochar life cycle analyses, the analyses for the life cycle of biochar systems and drafted the manuscript. VR provided technical supervision and was also directly associated with editing and reviewing the manuscript.

Open Access This article is distributed under the terms of the Creative Commons Attribution License which permits any use, distribution, and reproduction in any medium, provided the original author(s) and the source are credited.

\section{References}

1. Boden, T.A., Marland, G., Andres, R.J.: Global, regional, and national fossil-fuel $\mathrm{CO}_{2}$ emissions. Carbon Dioxide Information Analysis Center, Oak Ridge National Laboratory, U.S. Department of Energy, Oak Ridge, Tenn., USA (2010). doi 10.3334/ CDIAC/00001_V2010

2. U.S. Census Bureau: International Programs, International Data Base, World midyear population 1995-2050. http://www.census. gov/population/international/data/idb/worldpopgraph.php (2013). Accessed 24 April 2013

3. Environment Canada: National Inventory Report 1990-2011: Greenhouse Gas Sources and Sinks in Canada-Executive Summary. http://www.ec.gc.ca/ges-ghg/default.asp?lang=En\&n=68EE2 06C-1\&offset $=1 \&$ toc $=$ show (2013). Accessed 28 June 2013

4. Agriculture and Agri Food Canada (AAFC): Agriculture Residue. http://www4.agr.gc.ca/AAFC-AAC/display-afficher.do?id=1226 510406028\&lang=eng (2008). Accessed 6 April 2013

5. Statistics Canada: Human Activity and the Environment: Annual Statistics. Catalogue no. 16-201-X. http://www.statcan.gc.ca/pub/ 16-201-x/16-201-x2009000-eng.pdf (2009). Accessed 28 June 2013

6. Lehmann, J.: Bio-energy in the black. Front. Ecol. Environ. 5(7), 381-387 (2007)

7. Wu, H., Abdullah, H.: Biochar as a fuel: 1. Properties and grindability of biochars produced from the pyrolysis of Mallee wood under slow-heating conditions. Energy Fuels 23(8), 4174-4181 (2009)

8. Joseph, S., Peacocke, C., Lehmann, J., Munroe, P.: Biochar for Environmental Management, Science and Technology. In: Lehmann, J., Joseph, S. (eds.), Earthscan, London (2009, ISBN:9781-84407-658-1)

9. Kleiner, K.: The bright prospect of biochar. Nature Reports Climate Change, Issue 6. http://www.nature.com/reports/clima techange (2009). Accessed 6 April 2013
10. Dutta, B., Raghavan, G.S.V., Ngadi, M.: Surface characterization and classification of slow and fast pyrolysed biochar using novel methods of pycnometry and hyper-spectral imaging. J. Wood Chem. Technol. 32(2), 105-120 (2012)

11. Brownsort, P.A.: Biomass pyrolysis processes: performance parameters and their influence on biochar system benefits. http:// hdl.handle.net/1842/3116 (2009). Accessed 28 June 2013

12. Cooper, J.S., Vigon, B.: Life Cycle Engineering Guidelines. EPA/ 600/R-01/101 Cincinnati, OH: National Risk Management Research Laboratory, Office of Research and Development, USEPA. http://nepis.epa.gov/Adobe/PDF/P10071L2.pdf. (2001). Accessed 6 April 2013

13. Whitman, T., Yanni, S.F., Whalen, J.K.: Life cycle assessment of corn stover production for cellulosic ethanol in Quebec. Can. J. Soil Sci. 91(6), 997-1012 (2011)

14. Krull, E.: From source to sink: A national initiative for biochar research. In: Congress Symposium 7, pp. 8-10. Soil Carbon Sequestration, 19th World Congress of Soil Science: Soil Solutions for a Changing World (1-6 August 2010, Brisbane, Australia). http://www.iuss.org/19th\%20WCSS/Symposium/pdf/CS7. pdf (2010). Accessed 6 April 2013

15. Roberts, K.G., Gloy, B.A., Joseph, S., Scott, N.R., Lehmann, J.: Life cycle assessment of biochar systems: estimating the energetic, economic, and climate change potential. Environ. Sci. Technol. 44(2), 827-833 (2010)

16. Gaunt, J., Lehmann, J.: Energy balance and emissions associated with biochar sequestration and pyrolysis bioenergy production. Environ. Sci. Technol. 42, 4152-4158 (2008)

17. Sparrevik, M., Field, J., Martinsen, V., Breedveld, G.D., Cornelissen, G.: Life cycle assessment to evaluate the environmental impact of biochar implementation in conservation agriculture in Zambia. Environ. Sci. Technol. 47(3), 1206-1215 (2012)

18. Woolf, D., Amonette, J.E., Street-Perrott, F.A., Lehmann, J., Joseph, S.: Sustainable biochar to mitigate global climate change. Nat. Commun. 1(5), 1-9 (2010)

19. Hammond, J., Shackley, S., Sohi, S., Brownsort, P.: Life cycle analysis for pyrolysis biochar systems in the UK. Poster presented at the 3rd Annual conference of International Biochar Initiative (IBI), Rio De Janeiro, Brazil. UK Biochar Research Centre. http://www.biochar.org.uk/abstract.php?id=35 (2009). Accessed 6 April 2013

20. Statistics Canada: Principal field crop production, by province, 2010. Canada Year Book 2011. Catalogue no. 11-402-X (2012)

21. Intergovernmental Panel on Climate Change (IPCC): IPCC Guidelines for National Greenhouse Gas Inventories: Workbook, Revised 1996. http://www.ipcc-nggip.iges.or.jp/public/gl/invs1. html (1996). Accessed 6 April 2013

22. Mortimer, N.D., ElSayed, M.A.: North East biofuel supply chain carbon intensity assessment. Castle Square, Sheffield, UK: North Energy Associates Ltd. http://www.plateforme-biocarburants.ch/ medias/northenergy_2006.pdf (2006). Accessed 6 April 2013

23. McHargue, J.R., Roy, W.R.: Mineral and nitrogen content of the leaves of some forest trees at different times in the growing season. Bot. Gaz. 94(2), 381-393 (1932)

24. Fernández, F.: What is the nutrient value of corn stover removal? The Bulletin (University of Illinois Extension) 23(9). http://bul letin.ipm.illinois.edu/print.php?id=860 (2007). Accessed 6 April 2013

25. Agriculture and Agri Food Canada (AAFC): Canadian farm fuel and fertilizer: prices and expenses, march 2012. Mark. Outlook Rep. 4(1), 1-8 (2012)

26. Canadian Gas Association (CGA): Natural gas prices, monthly from henry hub index in December 2012. http://www.cga.ca/wpcontent/uploads/2011/02/Chart-3-Natural-Gas-Price20.pdf (2013). Accessed 10 April 2013 
27. Koch, D.: Mixed alcohol, diesel and syngas synthesis from forest residues via gasification: an economic analysis. https://smartech. gatech.edu/handle/1853/28131 (2008). Accessed 6 April 2013

28. Conversion and Resource Evaluation Ltd.: Economics and greenhouse gas emissions in the synthesis of biochar by pyrolysis. http://www.enviro-news.com/article/economics_and_greenhouse_ gas_emissions_in_the_synthesis_of_biochar_by_pyrolysis.html (2009). Accessed 6 April 2013

29. McCarl, B.A., Peacocke, C., Chrisman, R., Kung, C.-C., Sands, R.D.: Economics of biochar production, utilization and greenhouse gas offsets. In: Lehmann, J., Joseph, S. (eds.) Biochar for Environmental Management: Science and Technology, pp. 341-358. Earthscan, London (2009)

30. Howarth, R.W.: Preliminary assessment of the greenhouse gas emissions from natural gas obtained by hydraulic fracturing. Department of Ecology and Evolutionary Biology, Cornell University. http://cce.cornell.edu/EnergyClimateChange/NaturalGas Dev/Documents/PDFs/GHG\%20emissions\%20from\%20Marcel lus $\% 20$ Shale $\% 20-\% 20$ April $\% 201 \% 202010 \% 20$ draft.pdf (2010). Accessed 5 Sep 2013

31. McLaughlin, H., Anderson, P.S., Shields, F.E., Reed, T.B.: All biochars are not created equal, and how to tell them apart. In: North American Biochars Conference, pp. 9-12. Boulder, CO, USA (2009)
Baishali Dutta is a Ph.D. scholar in the Department of Bioresource Engineering of McGill University, Canada. She obtained her M.Sc. (Bioresource Engineering) also from McGill University, Canada and B.E. (Biotechnology) from India. Her research interests consist of addressing crucial environmental issues of climate change while providing sustainable alternative sources of energy on a global scale.

Vijaya Raghavan is currently a James McGill Professor in the Department of Bioresource Engineering of McGill University, Canada. VR obtained his B.E. (mechanical engineering) from Bangalore University, India, his M.Sc. (agricultural engineering) from the University of Guelph, Canada, and his Ph.D. (agricultural engineering) from Colorado State University, USA. He became an assistant professor in 1977, an associate professor in 1983, and a full professor in 1987 at the Department of Agricultural Engineering at Macdonald Campus in McGill University. He was Chair of the Department from 1993 to 2003, and has been the recipient of a James McGill Professor award since 2002. The main thrust of his research efforts over the past two decades has been to study and develop postharvest or post-production processes and technologies for the storage and drying of produce and crops. His research activities have also touched on other areas such as soil compaction and tillage practices, biofuels, and microbial fuel cells. 